\title{
JUURNAL.RU
}

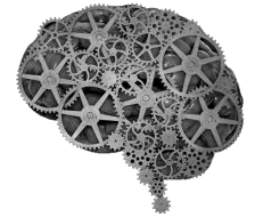

COMPANY GROUP "INTELLEKT"

\author{
Суюнова Г. Б, Белинская Р. А. \\ Институт сервиса, туризма и дизайна (филиал) СКФУ в г. Пятигорске
}

Пятигорск, Россия

doi: 10.18411/lj2016-5-5-02

\section{Сравнительный анализ систем автоматизации гостиничных предприятий г. Пятигорска}

В наше динамичное время трудно представить современный отель без системы автоматизации, где процесс оформления заезда и отъезда проводится вручную, медленно, и гости вынуждены тратить время на раздражающее ожидание в очереди, служащим необходимо заполнять огромное количество документации, уточнять у обслуживающего персонала состояние номеров после выселения и т. д. Все современные гостиницы, желая идти в ногу с развивающимися технологиями этой области и получать максимум прибыли от своей работы, тем самым повышая качество выполняемых операций, стараются применять системы автоматизации, зарекомендовавшие себя в индустрии гостеприимства: «Русский отель», Opera PMS, Fidelio, Shelter, Lodging Touch и другие. В Пятигорске, как и в любом другом городе, большое количество гостиниц, и в каждой из них используют определённую автоматизированную информационную систему. [1]

Было проведено небольшое исследование, с целью выяснить, какое программное обеспечение используют в гостиницах нашего города. Для исследования были выбраны следующие заведения: Бизнес-отель «Бештау», Конгресс-отель «Интурист», Спа-отель «Бристоль», Гостиничный комплекс «Затерянный рай у Машука» и Хостел «Жить просто». Выбор гостиниц обусловлен разнородностью внутренней специфики, что, в принципе, отражено 
в названиях отелей.

Так, Бизнес-отель «Бештау» - восьмиэтажный гостиничный комплекс, расположенный в деловом центре Пятигорска. В структуре данного отеля 183 комфортабельных номера, ресторан «Бештау» и лобби-бар, конференц-центр с тремя залами, комната переговоров и просторный холл для кофе-брейков, спортклуб «Бештау» с плавательным бассейном, тренажёрным залом, кардиозоной, турецкой баней, финской сауной и фитнес-баром. [5] Конгрессотель «Интурист» располагает 153 комфортабельными номерами (от стандартного до апартаментов), находящихся в шестнадцатиэтажном здании. В «Интуристе» также имеются кафе-клуб «Рандеву», банкетный зал «Император», дегустационный зал - магазин «Вина Прасковеи», караоке-бар, салон красоты, массажный кабинет, сауна, бильярдный клуб и, конечно, Конгресс-Холл вместимостью до 220 человек, который трансформируется в зал «Ассамблея»до 70 человек или в зал «Форум» - до 100 человек либо «Бизнес-Холл» вместимостью до 50 человек, комната переговоров - вместимостью до 30 человек. [4] Спа-отель «Бристоль» - это четырёхэтажный отель, расположенный в исторической и культурной части города, в курортной зоне, недалеко от парка «Цветник». В отеле 30 номеров повышенной комфортности авторского дизайна, ресторан a la carte (европейская и кавказская кухни) с широким ассортиментом рыбных блюд, бизнес-центр до 10-ти посадочных мест, конференц-зал до 50-ти посадочных мест, современный спа-центр с бассейном и хамамом. [6] Гостиничный комплекс «Затерянный рай у Машука» включает в себя 19 номеров, расположенных в шести уютных коттеджах, ресторан на 50 мест, находящийся на втором этаже основного здания, конференц-зал до 30-ти посадочных мест, комнату отдыха на третьем этаже, открытый бассейн, сауну и гейзерный бассейн на первом этаже основного здания. [7] Хостел «Жить просто» - мини-гостиница с 26 номерами различного типа, общей кухней, гостиной со спутниковым телевидением и прачечной. [8]

Как показало исследование, использование той или иной системы 
автоматизации определяется рядом различных факторов, прежде всего объёмами номерного фонда и спектром специфических услуг, предоставляемых отелями. Так, для «Интуриста» важно наличие удобных модулей для проведения конференций и мероприятий различного масштаба. «Бристоль» и «Бештау» нуждаются в системе с широкими функциональными возможностями предоставления ряда услуг, отражающих специфику названных отелей. Выбирая систему автоматизации для гостиницы «Затерянный рай у Машука», стоит обратить внимание на её расположение (в лесном массиве горы Машук) и небольшой номерной фонд, предназначенный больше для отдыха от городской суеты.

Каким же системам автоматизации отдают своё предпочтение вышеуказанные гостиницы нашего города, и чем они руководствуются при их выборе?

Итак, в «Бристоль» и Бизнес-отеле «Бештау» используют систему управления гостиницей Shelter. Программа оснащена информативной «шахматкой», удобной в использовании. Имеется функция киоска, предоставляющая возможность продавать товары и услуги гостям, не отдыхающим в отеле, что очень практично для данных гостиниц, в связи с их расположением. Помимо перечисленных преимуществ, Shelter имеет менеджер мероприятий (отдельный от шахматки), в нём можно забронировать дополнительные услуги, настраивать скидки на использование этих услуг и выставлять счета за них. Гостиничная система автоматизации Shelter разработана компанией UCS. C помощью системы управления гостиницей Shelter можно автоматизировать заведение любого формата: гостиницу, санаторий, хостел, пансионат, базу отдыха, апарт-отель. Программа оптимизирует процессы заселения (выселения), бронирования, работу со счетами гостей и т. д. Система охватывает все секторы гостиничного хозяйства начиная от прачечной и заканчивая службой маркетинга. Система объединяет в единое информационное пространство работу службы портье, бухгалтерии и 
финансовой службы, отдела продаж, хозяйственной и банкетной служб, делая работу гостиницы прозрачной и контролируемой. Система Shelter полностью отвечает требованиям российского законодательства, обеспечивая защиту персональных данных, работу с фискальными регистраторами, разрешёнными к использованию в гостиничном бизнесе, регистрацию российских и иностранных граждан с выгрузкой данных в УФМС. Информационная система Shelter работает с системой управления рестораном R-Keeper, программой автоматизации фитнес-клуба и СПА-Абонемент, складской учётной системой StoreHouse. Также программа взаимодействует $\mathrm{c}$ платёжной системой ReserveMaster и с системами управления продажами Channel Manager WuBook и Travelline Channel Manager, позволяя напрямую из программы Shelter управлять различными каналами продаж одновременно: HRS, Hotel.de, Expedia, Agoda, Booking.com, OKTOGO, Sabre, BBPlanet, HostelsClub, Ваш отель и многими другими. Программа Shelter работает с различными замковыми системами, фискальными регистраторами, телефонными станциями. Максимально удобный и интуитивно понятный интерфейс данной программы упрощает работу администратора:

- использование различных «горячих» клавиш;

- возможность одновременной работы с несколькими бронями, поселениями, фолио;

- открытие окон в новых вкладках;

- иконки для быстрой ориентации в функционале кнопок управления;

- возможность самостоятельной настройки внешнего вида программы: использование изображений, подсказок на локациях, изменение цветовой схемы.

- С помощью программы можно управлять внутренними ресурсами гостиницы:

• управление службами сервиса гостиницы; 
- контроль состояния номерного фонда;

- организация бюро находок;

- ведение справочника номеров и индивидуальных особенностей комнат (окна с видом на море);

- планирование и контроль работы горничных;

- анализ текущего состояния номеров: управление статусом номера (чистый, грязный), отметки о расходе средств на уборку; получение отчётов о работе службы горничных;

- бронирование услуг конференц- и банкетных залов, развлекательных центров;

- возможность определения меню (из базы R-Keерег) для банкетов, кофе-брейков;

- формирование отчётов по проводимым мероприятиям для различных служб гостиницы.

Система поддерживает иерархические счета (фолио). Информация о предоставленных гостю услугах: совершённых звонках, просмотре платного телевидения и прочее, автоматически заносится на счёт гостя. С помощью Shelter v.2 можно оборудовать отель устройством управления светом и контролировать подачу электроэнергии. Электричество будет подаваться в номер заселении гостя, а при его отъезде - отключаться. Это поможет повысить качество контроля продажи номеров, следовательно, исключить несанкционированные продажи номерного фонда персоналом. Минусом данной системы считается слабый уровень технической поддержки. Несмотря на такой недостаток, «Бристоль» и «Бештау» продолжают её использовать, так как она обладает всем необходимым функционалом, который требуется для осуществления успешной и комфортной деятельности предприятия. [3]

В гостиничном комплексе «Затерянный рай у Машука» применяют систему управления Отель Стандарт. Важным преимуществом данной 
программы для гостиницы является возможность исключить оплату наличными в точках продаж отеля (ресторан, гейзерный и открытый бассейны, сауна), заменив на депозитный или кредитный принцип обслуживания клиентов. Ещё одним плюсом, несомненно, считается наличие необходимых гостям справочных данных по региону и телефонным номерам, которые хранятся в Отель Стандарт и распечатываются по просьбе гостя. Система управления отелями Отель Стандарт является современной системой автоматизации, полностью отвечающей требованиям менеджмента предприятия по качественной и эффективной работе персонала, и оправдывающей ожидания гостей по высокому уровню сервиса. Отель Стандарт включает в себя необходимые составляющие для объединения работы служб гостиницы: «Фронт офис»: служба ресепшен - приём и размещение гостей, ведёт учёт постоянных и VIP гостей, начисление баллов и прочее, служба бронирования - включает работу с групповыми заездами. При бронировании данная система анализирует наличие комнат на период, который требуется гостю и предлагает наиболее приемлемый вариант, учитываются существующие тарифные планы, заполняется карта гостя. При заселении система выдаёт информацию о состоянии номерного фонда гостиницы (учитываются комнаты, находящиеся на ремонте, закрытые для продажи, не убранные горничными) и распечатывает карту гостя. В системе Отель Стандарт ведётся учёт основных и дополнительных услуг (платных и бесплатных) на карту гостя, система позволяет перемещать и корректировать начисления на разных счетах, учитывает формы оплаты. Все расчёты производит администратор на ресепшене. При выезде система архивирует данные в истории гостей отеля и предоставляет полный отчёт по всем услугам, которыми пользовался гость. С помощью системы можно отслеживать задержки оплат клиентов. Используя Отель стандарт можно определять показатели работы гостиницы за прошедший день (процент загрузки, количество выбывших и прибывших гостей, доход и прочее.). В данной системе ведётся организация всех существующих тарифов в 
гостинице, включая разнообразные формы пансиона (завтрак, полупансион, полный, всё включено). Система предоставляет возможность получать отчёты о деятельности гостиницы: Службы бронирования, Службы приёма и размещения, Службы гостиничного хозяйства и Службы номерного фонда, Финансовая отчётность и т. д. Руководство гостиницы отдает предпочтение именно этой системе автоматизации, так как она обеспечивает работу необходимых для гостиницы функций и имеет более низкую стоимость в сравнении с другими системами (Shelter, Fidelio), что выгодно в связи с небольшим номерным фондом отеля. [9]

В Конгресс-отеле «Интурист» используется известнейшая система управления гостиницей Fidelio. Программа имеет удобный поиск и быструю навигацию, что облегчает работу персонала при большом потоке туристов и участников конференций или мероприятий. $\mathrm{C}$ помощью кредитов для горничных можно регулировать объём работы, для их равномерной нагрузки и улучшить качество уборки. Система управления гостиницей Fidelio состоит из нескольких модулей: бронирование, управление блоками (анализ блоков комнат, просмотр и их создание), регистрация и выписка гостей (отображение статусов комнат, поэтажных планов, создание отчётов), пакетирование услуг, управление тарифами. Система универсальна в своём использовании: пользователь может выполнять собственные определения, Fidelio легко адаптируется для гостиниц любого класса и размера. Основные элементы, обеспечивающие гибкость системы, включают в себя: блок раскраски экрана (Screen Painter), различные параметры установки, генератор отчётов (Report Generator), определяемые пользователем пиктограммы, ночной аудит и меню отчётов, неограниченные уровни защиты. Fidelio имеет стандартный и понятный интерфейс, позволяющий служащим гостиницы легко научиться работать с системой. Модуль бронирования в данной программе позволяет выполнять множество подзадач: вести базу данных гостей, просматривать информацию о наличии номеров, бронировать комнаты для различных категорий гостей, вести учёт и 
статистику, и другие. Модуль отчётов подготавливает различные данные о состоянии номеров, проживающих гостях, заполнении гостиницы, текущем финансовом положении. Система Fidelio работает совместно с расчётно кассовым комплексом для ресторанов Micros, программой автоматизации финансово - хозяйственной деятельности HRS Back Office, программой ведения складских операций Fidelio Food \& Beverage, программой организации отдела продаж и мероприятий Sales \& Catering и программой главного инженера EMS. Fidelio включает в себя модуль бронирования (Reservation Module), с его помощью можно производить различные типы бронирования: индивидуальное, исходное, для компании, для туристского агентства, для группы. Система позволяет определить часто проживающего гостя по его номеру (frequent guest membership number), агента по туризму по номеру IATA и компании по корпоративному идентификатору (ID). В системе существует модуль блоков Blocks, который обеспечивает создание блока номеров, объединение в блок любой комбинации типов номеров с различными расценками, ввод определённого срока окончания бронирования, создание серии экскурсий для блоков, создание списка номеров комнат для группы, варианты совместных расценок, индивидуальную обработку данных каждого члена группы, распечатку ключей для всей группы, установку индивидуальных платежей, групповой или индивидуальный выезд, и другие. Модуль пакетов Packages предоставляет гостю дополнительное обслуживание и оплачивается отдельно. Например, пакет «романтическое предложение» включает в себя скидку на номер, приветственную бутылку домашнего вина и тарелку с фруктами, а также завтрак в номер и бутылку шампанского. Модуль планирования досуга Leisure Module представляет собой систему бронирования деятельности на определённый период времени: игра в гольф, массаж, верховая езда и т. д. Минус программы - отсутствие функции, выставляющей ранние заезды и поздние выезды. При большой загрузке отеля персоналу приходится дублировать все данные на бумаге. Учитывая специфику данного отеля (отель 
больше предназначен для деловых встреч и проведения массовых мероприятий), можно утверждать, что выбор именно этой системы управления обоснован наличием удобного модуля конференций room planner, который позволяет моделировать необходимую обстановку в конференц-зале для любого мероприятия. [2]

В Хостеле «Жить просто» системы автоматизации гостиничной деятельности как таковой нет, и, все действия персонал выполняет вручную. Это обусловлено тем, что гостиница не имеет большого потока туристов, располагает маленьким номерным фондом и как следствие, относительно невысоким уровнем доходов. Следует отметить, что отсутствие системы управления гостиницей значительно снижает скорость и качество выполнения работы персоналом. В небольших гостиницах Пятигорска обычно не используются автоматизированные информационные системы из-за их относительной дороговизны. В связи с этим возникает потребность в разработке более доступных решений для автоматизации гостиниц, которые не будут уступать по качеству своим недешёвым аналогам. Например, у компании UCS, предлагающей свою систему Shelter для гостиниц, существует бюджетная версия для мини-отелей Shelter Lite, которая обладает ограниченным функционалом, но не менее низкой ценой из-за известности «имени».

В Пятигорске, как и во многих других небольших городах, каких в России немало, функционирует огромное количество мини-гостиниц, руководство которых считает невыгодным использование существующих систем автоматизации, так как в этих гостиницах не требуется использование большей части функций, предоставляемых в системах. Необходимо создание такой системы автоматизации гостиничного предприятия, которая будет обладать функциями, требующимися для гостиниц с небольшим номерным фондом, и не будет включать в себя лишние. Такая система будет востребована из-за удобства в использовании, значительно низкой стоимости продукта и качества на 
должном уровне, которое возможно будет обеспечить намного проще в связи с упрощённым функционалом системы.

\section{Литература:}

1. Есаулова С. П. Информационные технологии в туристической индустрии: учеб. пособие /С.П. Есаулова. - М.: Дашков и Ко, 2011. - 152 c.

2. Fidelio Software Documentation

3. http://tech-success.ru

4. http://www.hotel-intourist.ru

5. http://www.hotel-beshtau.ru

6. http://spahotel-bristol.ru

7. http://www.z-rai.ru

8. http://www.zhitprostohostel.ru

9. https://www.del-fin.ru/old/ 